\title{
EDUCAÇÃO AMBIENTAL E RISCO DE DESASTRES NATURAIS: ANÁLISE INTEGRADA DA PERCEPÇÃO DE ALUNOS E PROFESSORES DE UMA ESCOLA EM MACAÉ (RJ)
}

\author{
Gildo Rafael de Almeida Santana ${ }^{1}$ \\ Eliane Barbosa Santos ${ }^{2}$ \\ Cibele Rosa Gracioli ${ }^{3}$
}

Resumo: Este trabalho avaliou a percepção de risco de alunos e professores quanto a ocorrência de desastres naturais e a inserção da Educação Ambiental em uma escola em Macaé-RJ. Os dados obtidos através de questionários, indicam que a escola em análise não aborda o tema desastres naturais. Para os professores, o motivo é a falta de materiais (33\%) e conhecimento na área (67\%), corroborando com a resposta dos alunos (45\% em média) que afirmaram não ter ouvido falar sobre o tema na escola. Diante disso, ações formativas de sensibilização visando a diminuição da vulnerabilidade de risco são cada vez mais necessárias. Já as ações de Educação Ambiental podem ser realizadas por meio de oficinas lúdicas, saídas de campo. Já as ações de Educação Ambiental podem ser realizadas por meio de oficinas lúdicas, saídas de campo etc.

Palavras-chave: Percepção de Risco; Vulnerabilidade Socioambiental; Região Norte Fluminense; Educação; Meio Ambiente.

Abstract: This work evaluated the risk perception of students and teachers regarding the occurrence of natural disasters and the inclusion of environmental education in a school in Macaé-RJ. The data obtained through questionnaires indicate that the school under analysis does not address the topic of natural disasters. For teachers, the reason is lack of materials (33\%) and knowledge in the area (67\%), corroborating the response of students ( $45 \%$ on average) who said they had not heard about the topic at school. In view of this, awareness-raising training actions aimed at reducing risk vulnerability are increasingly necessary. Environmental education actions, on the other hand, can be carried out through playful workshops, field trips. Environmental Education actions can be carried out through playful workshops, field trips, etc.

Keywords: Perception of Risk; Socio-environmental Vulnerability; Northern Fluminense Region; Education; Environment. 


\section{Introdução}

A interferência humana tem gerado ao longo dos tempos o agravamento das consequências das alterações no meio ambiente. Com isso, nota-se que a Educação Ambiental (EA) vem sendo amplamente discutida como um fator de suma importância para a melhoria da qualidade socioambiental, haja vista que os impactos ao meio ambiente e as ocorrências de desastres naturais têm se intensificado, o que reforça a importância da inserção da EA nos espaços formais e não formais.

Os desastres naturais podem ocasionar grandes e pequenos impactos na sociedade, sendo muitas vezes potencializados pela ocupação e intervenção humana em áreas caracterizadas como sendo de perigo geológico. Essa vulnerabilidade, pode ser definida como sendo um conjunto de fatores socioeconômicos, políticos, ideológicos, educacionais e culturais. No entanto, a vulnerabilidade se reduz através da capacidade que uma comunidade tem em enfrentar os perigos e de se recuperar dos desastres. Logo, a vulnerabilidade é maior quando o perigo é desconhecido e quanto mais vulnerável a comunidade, maior será o impacto do desastre e o dano potencial (AMARAL; GUTJAHR, 2011).

Embora o município de Macaé-RJ se destaque no cenário internacional como a "capital nacional do petróleo brasileiro", localmente, apresenta grande vulnerabilidade a ocorrência de desastres naturais. Nos últimos anos, por exemplo, as fortes chuvas atingiram o município, causaram interdições em rodovias, queda de ponte, alagamento de ruas, deslizamentos de encostas e mortes.

As ocorrências de desastres naturais como enchentes, inundações e alagamentos estão muitas vezes associadas a impermeabilização do solo, a disposição inadequada de resíduos, a ocupação das margens dos cursos d'água e ao desmatamento. Aliado a esses fatores, o crescimento desordenado das cidades, muitas vezes em áreas impróprias a ocupação, aumenta a vulnerabilidade das comunidades ao risco de desastres naturais. Portanto, as implicações dos desastres, também estão relacionadas as ações do homem. Diante disso, são necessárias ações de EA com o propósito de concorrer para a conservação e o uso sustentável dos recursos naturais, ajudar na solução de problemas socioambientais, contribuir para uma melhor qualidade de vida da população e, proporcionar aos indivíduos, embasamento teórico para uma reflexão sobre a sua condição real no ambiente ao qual está inserido.

Neste sentido, o educador torna-se um articulador das condições necessárias para o desenvolvimento do cidadão crítico e capaz de agir em situações práticas. Portanto, faz-se necessário verificar como alunos e professores percebem os riscos de desastres naturais e de que forma este tema vem sendo trabalhado nas escolas. Assim como, verificar como os professores vêm trabalhando a EA na escola. 


\section{Metodologia}

\section{Caracterização da área de estudo}

Macaé, área de estudo deste trabalho, é um dos 92 municípios do Estado do Rio de Janeiro e um dos 9 que formam a região Norte Fluminense (NF) (Figura 1). Segundo dados do Instituto Brasileiro de Geografia e Estatística (IBGE, 2010), a região NF apresenta uma população de 849.515 habitantes, $9.745 \mathrm{~km}^{2}$ de área e densidade demográfica de 87 habitantes $/ \mathrm{Km}^{2}$; já Macaé, possui uma população de aproximadamente 207 mil habitantes, $1.217 \mathrm{Km}^{2}$ de área e uma densidade demográfica de $170\left(\mathrm{Hab} / \mathrm{Km}^{2}\right)$.

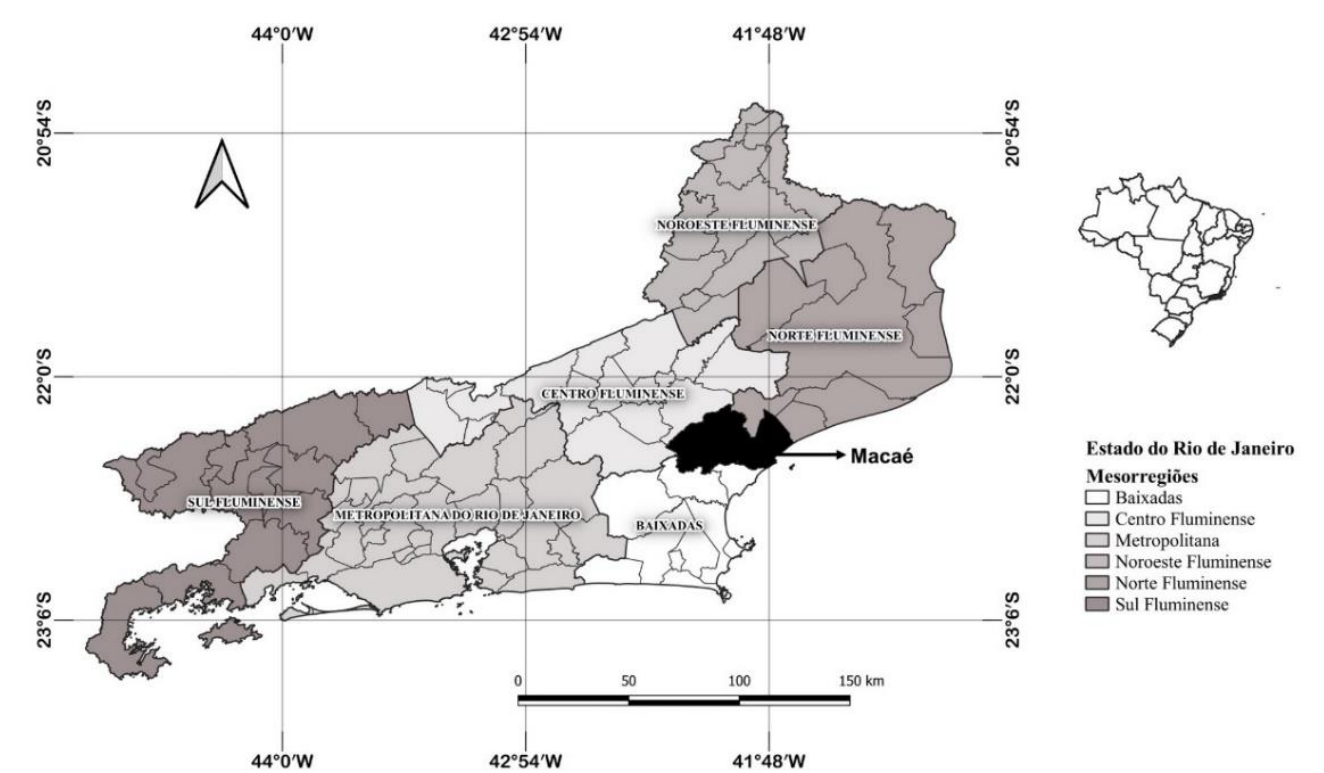

Figura 1: Localização do Estado do Rio de Janeiro, com ênfase nas mesorregiões e município de Macaé.

Fonte: Elaborado pelo Autores.

Tradicionalmente, a agroindústria açucareira caracterizou a região NF. Todavia, nos últimos anos as atividades ligadas ao petróleo e ao gás natural têm assumido um papel importantíssimo na economia regional, destacando-a como uma das principais regiões do Estado. A exploração do petróleo e do gás natural é o principal fator que impulsionou o crescimento do PIB do Estado do Rio de Janeiro, assim como as receitas dos municípios da região NF, principalmente dos municípios de Campos dos Goytacazes, Macaé, Quissamã, São João da Barra e Carapebus, que tiveram considerável aumento devido ao recebimento dos royalties destes produtos (CEEP, 2018). 


\section{Tipo de Pesquisa}

O presente trabalho caracteriza-se como descritivo, que é o estudo e descrição das características. De acordo com Gil (2002), este tipo de pesquisa tem como objetivo primordial a descrição das características de determinada população ou fenômeno, ou então, o estabelecimento de relações entre variáveis.

No que se refere ao procedimento adotado neste estudo, enquadra-se o método de levantamento ou survey, tendo em vista que a pesquisa se desenvolveu por meio da aplicação de questionário. Este tipo de pesquisa, visa determinar informações sobre práticas ou opiniões atuais de uma população específica. Em geral, serve para pesquisas descritivas que pretendem dizer através da população selecionada, quantas pessoas têm determinados atributos, ou até mesmo explorar aspectos de uma situação, procurar explicações, entre outros (SOUZA, 2010). No caso deste estudo, pretende-se explorar os aspectos da percepção de risco quanto aos desastres naturais, tendo como público-alvo alunos e professores do ensino fundamental I.

\section{Desenvolvimento das Ações}

Os questionários utilizados neste estudo foram anônimos e continham 4 (para alunos) e 6 (para professores) questões de múltipla escolha que buscaram identificar, além da inserção da EA na escola, a percepção de risco quanto a ocorrência de desastres naturais.

Os questionários foram aplicados no ano de 2018 em parceria com o projeto de extensão "Desastres Naturais e Sua Abordagem no Ambiente Escolar" desenvolvido pelo Laboratório de Meteorologia (LAMET) da Universidade Estadual do Norte Fluminense Darcy Ribeiro (UENF) e foram aplicados com professores e alunos do $3^{\circ}, 4^{\circ}$ e $5^{\circ}$ ano de uma escola municipal de ensino fundamental I, localizada na zona rural do município de Macaé (Estado do Rio de Janeiro). Ao todo, participaram deste estudo, 14 alunos do $3^{\circ}$ ano, 13 alunos do $4^{\circ}$ ano, 13 alunos do $5^{\circ}$ ano e 9 professores, totalizando 49 entrevistados. Para a análise e discussão dos resultados, os entrevistados serão identificados como alunos e professores.

Os resultados foram apresentados em gráficos do tipo pizza e barra, alguns com análise comparativa entre os dois grupos de entrevistados.

\section{Resultados e Discussões}

Dos 40 alunos entrevistados, $70 \%$ afirmaram já ter ouvido falar em desastres naturais (Figura 2a), desses alunos, 50\% ( $3^{\circ}$ ano) e $46 \%$ (4 ano) responderam já ter ouvido falar sobre o assunto na escola e, mais da metade $(62 \%)$ dos alunos do $5^{\circ}$ ano afirmaram que ouviram falar sobre o assunto na TV. Em média, $40 \%$ dos alunos afirmaram já ter ouvido falar em desastres naturais na escola e $45 \%$ ouviram falar sobre o assunto na TV (Figura $2 b$ ). 
a)

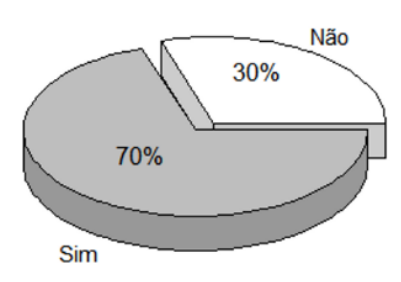

b)

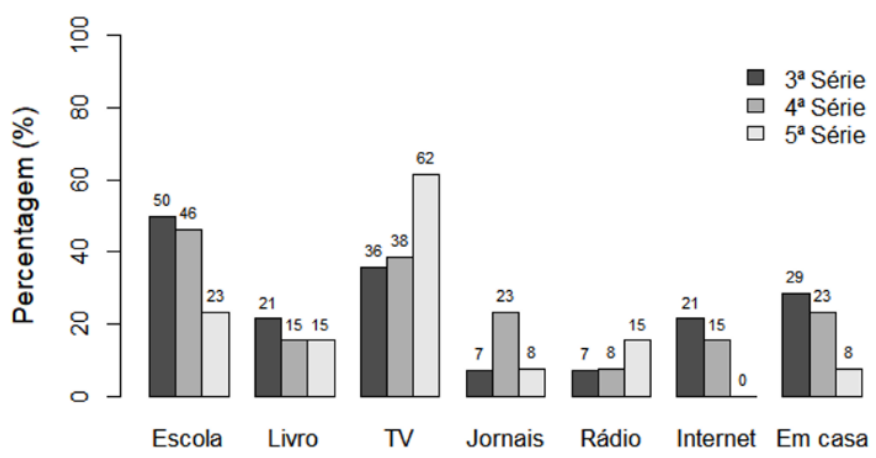

Figura 2: Respostas de alunos em porcentagem das perguntas: a) Você já ouviu falar em desastres naturais? e b) Se sim, onde? (Macaé, RJ, 2018).

Fonte: Elaborado pelo Autores.

Entende-se, que a escola é um alicerce e cumpre um importantíssimo papel na construção de uma sociedade capaz de tomar decisões individuais e coletivas em prol de um bem comum, assim como ser capaz de desenvolver capacidades de percepção e ação em momentos críticos. Neste sentido, ainda se faz necessário que sejam desenvolvidas ações para incentivar a abordagem do tema, pois apesar da escola ter sido, em média, o segundo meio mais indicado como fonte de conhecimento sobre o assunto, cerca de $60 \%$ dos alunos indicaram ter ouvido falar em desastre naturais por outros meios.

Como pode ser observado na Figura $3 \mathrm{a}$, apenas $30 \%$ dos alunos afirmaram que são desenvolvidos trabalhos sobre desastres naturais na escola e apenas $11 \%$ (Figura $3 b$ ) dos professores afirmaram que desenvolvem trabalhos sobre 0 assunto. Essas afirmações demostram que existe ainda uma carência da abordagem desse tema no ambiente escolar, apesar do município de Macaé ser vulnerável a ocorrência de desastres naturais, como inundações, alagamentos e deslizamento de terra.

a)

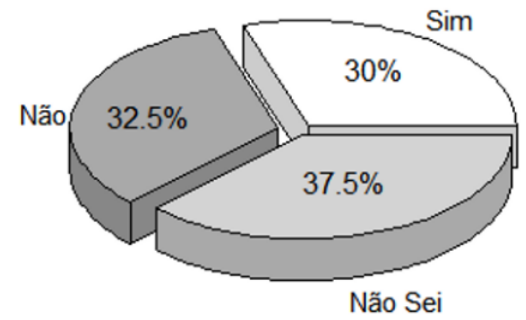

b)

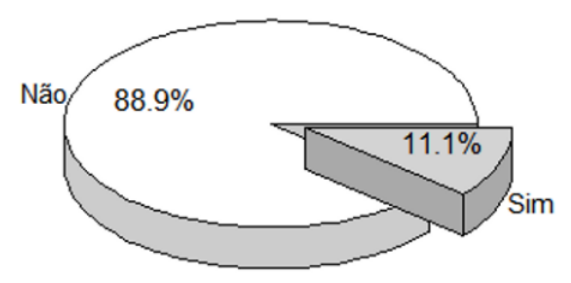

Figura 3: Resposta em porcentagem das perguntas (a) Para os alunos: Na sua escola são desenvolvidos trabalhos sobre desastres naturais? e (b) Para os professores: Na escola, você já realizou algum trabalho sobre desastres naturais? (Macaé, RJ, 2018).

Fonte: Elaborado pelo Autores. 
Vale ressaltar que a medida em que o ser humano ocupa espaços, alteram-se os padrões dos ecossistemas, contribuindo para mudanças na natureza. Assim, para entender que essas mudanças ocasionam novas vulnerabilidades, é necessário saber identificar um risco em potencial, tendo em vista que áreas mais populosas, a depender do tipo de ocupação, tendem a ser mais vulneráveis aos riscos de desastres naturais. A vulnerabilidade socioambiental e os desastres naturais estão conceitualmente relacionados atualmente e, diminuir a vulnerabilidade é criar condições para que determinado grupo possa se antever em alguns casos, entendendo que a vulnerabilidade é maior quando o perigo é desconhecido.

Para uma melhor compreensão dos resultados obtidos na Figura 3, foi perguntado aos alunos e professores "o que são desastres naturais?". $\mathrm{Na}$ Figura 4, observa-se que $50 \%$ dos alunos ( $3^{\circ}$ ano) e $69 \%$ dos alunos do $4^{\circ}$ e $5^{\circ}$ ano (Figura 4a) responderam que desastres naturais são eventos naturais como inundações, tsunami e terremoto. Ao mesmo tempo, $89 \%$ dos professores (Figura 4b), disseram que desastres naturais são fenômenos naturais que atingem regiões habitadas pelo homem, causando danos materiais e humanos. Para Amaral e Gutjahr (2011), desastre natural é o acontecimento de um fenômeno natural que modifica a superfície terrestre e atinge áreas ou regiões habitadas, causando danos materiais e humanos. Portanto, a maioria dos entrevistados (alunos e professores) compreendem o que são desastres naturais, o que pode contribuir para a diminuição da vulnerabilidade da comunidade em que estão inseridos.

a)

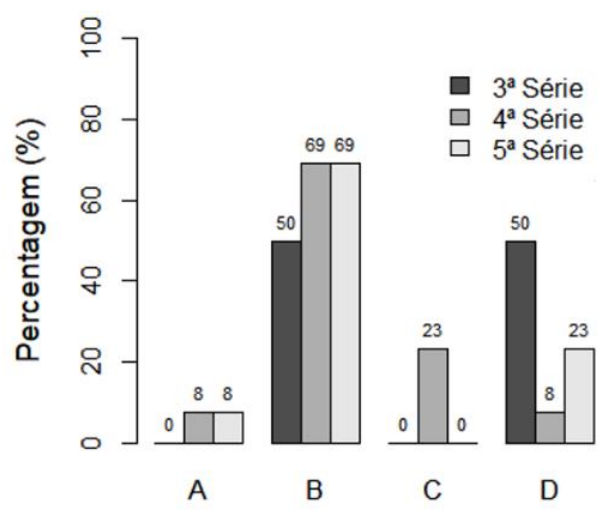

A - São eventos causados pelo homem;

B - São eventos naturais, como inundação, tsunami e terremoto:

C - São acidentes que causam mortes;

D - Não sei. b)

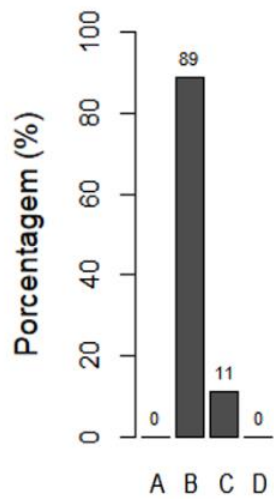

A - São eventos gerados pelas ações ou omissões humanas;

B - São fenômenos naturais que atingem regiões habitadas pelo homem, causando danos materiais e humanos;

C - São eventos que ocorrem devido à intervenção humana na natureza;

D - Não sei.

Figura 4: Resposta em porcentagem da pergunta: Em sua opinião, o que são desastres naturais? (a) Resposta dos alunos e (b) Resposta dos Professores. (Macaé, RJ, 2018).

Fonte: Elaborado pelo Autores. 
Outro questionamento levantado foi a percepção dos alunos frente ao tema meio ambiente. Na Figura 5 , pode-se notar que dos alunos

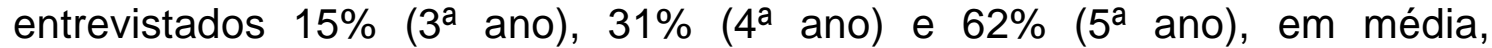
afirmaram que "meio ambiente é tudo que está a nossa volta e que fazem parte dele". Ainda assim, em média, $38 \%$ dos alunos do $3^{\text {a }}$ ano, $54 \%$ do $4^{\text {a }}$ ano e $23 \%$ do $5^{\text {a }}$ ano informaram que "meio ambiente é a natureza". Já, em torno de $38 \%$ dos alunos do $3^{\text {a }}$ ano ainda afirmaram que "meio ambiente são os animais e as plantas".

Segundo Toaldo e Meyne (2013), "meio ambiente é formado pela água, pelo ar, pelo solo, pela energia solar, e pelos seres vivos como a fauna e a flora", assim, seria correto afirmar que o homem se insere nesse contexto. No entanto, apenas cerca de $35,53 \%$ dos alunos entrevistados se incluíram como parte integrante do meio ambiente.

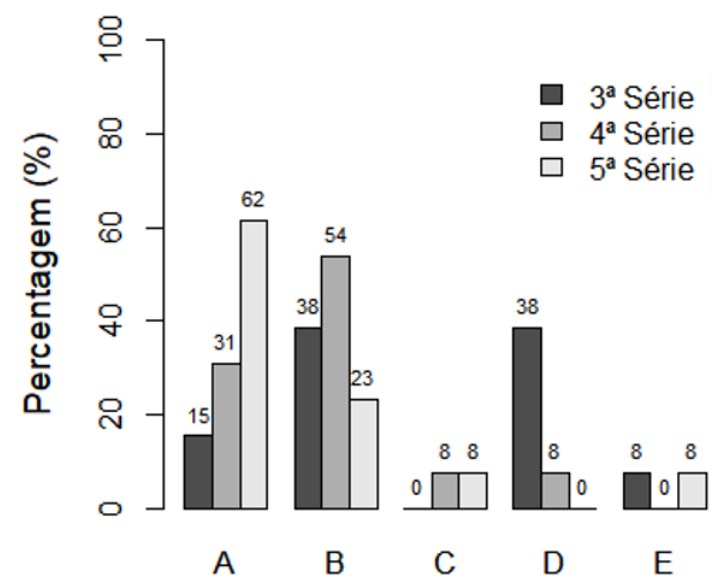

A - É tudo que está a nossa volta e eu faço parte dele;

B - A natureza;

C - São os seres vivos;

D - São os animais e as plantas;

E - Não sei.

Figura 5: Respostas dos alunos em porcentagem da pergunta: Para você, o que é meio ambiente? (Macaé, RJ, 2018).

Fonte: Elaborado pelo Autores.

$\mathrm{O}$ ato de perceber-se como parte integrante do meio ambiente, pode ser entendido como o desenvolvimento de uma consciência "ambiental" em relação ao meio em que se encontra inserido. A percepção, a reação e as respostas às ações sobre o meio em que vivem, diferem de indivíduo para indivíduo. Segundo Fernandes et al. (2004), essas respostas ou manifestações são resultados das percepções, tanto individuais quanto coletivas, dos processos de cognição, de julgamento e expectativas de cada indivíduo. Neste sentido, pode-se entender que a percepção integra as medidas de prevenção. 
Apesar de estar além da capacidade humana evitar que fenômenos naturais severos ocorram, é possível desenvolver através da prevenção, medidas que minimizem os impactos causados por estes fenômenos (KOBIYAMA et al., 2006). Para Kobiyama et al. (2004), há dois tipos de medidas básicas preventivas: as estruturais, que envolvem obras de engenharia $e$, as não-estruturais que geralmente envolvem ações de planejamento e gerenciamento, como sistemas de alerta e zoneamento ambiental. Neste sentido, para que haja a redução dos riscos de desastres naturais, é preciso que exista um comprometimento de longo prazo, tanto no método quanto na postura, de modo que estimule o progresso de cidades, estados e países. Para isso, a gestão do risco, deve ser planejada com foco na prevenção, "não na ajuda humanitária posterior ao ocorrido" (CARVALHO; DAMACENA, 2012).

Buscou-se saber, também, a frequência em que os professores abordam assuntos relacionados ao meio ambiente. Conforme ilustrado na Figura 6 , pode-se observar que em torno de $67 \%$ dos professores afirmaram que com alguma frequência abordam temas ligados ao meio ambiente. Portanto, apesar da maioria dos professores terem afirmado não desenvolver trabalhos sobre desastres naturais (Figura 3b), verifica-se (Figura 6) que eles buscam a inserção de temas ambientas, contribuindo para a sensibilização e o desenvolvimento de uma conscientização ambiental dos alunos. Essa conscientização, pode ser entendida como a mudança de comportamento, tanto em atitudes quanto em aspectos da vida, dos indivíduos e da sociedade em relação ao meio ambiente (BUTZKE et al., 2001). Assim, torna-se ainda mais evidente a necessidade de se realizar capacitações com estes profissionais de modo que se possa estimular a inserção da EA e de temas relacionados os desastres naturais dentro da escola.

a)

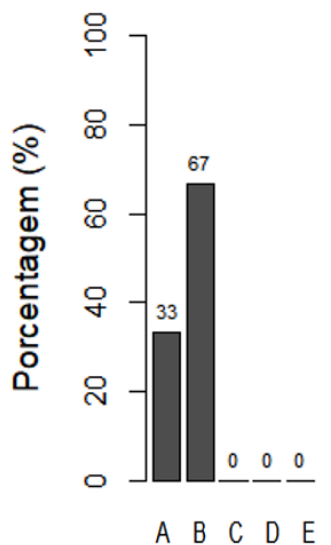

A-Sempre;

B - Com alguma frequência;

C - Raramente;

D - Nunca;

E - Não sei.
Figura 6: Respostas de professores em porcentagem da pergunta: Na escola, com que frequência são abordados assuntos ligados ao meio ambiente? (Macaé, RJ, 2018).

Fonte: Elaborado pelo Autores. 
Em outro questionamento, buscou-se identificar os aspectos da inserção da EA na escola. Pode-se observar na Figura 7 que a maioria dos professores entrevistados (89\%), afirmou realizar ou já ter realizado alguma ação de EA. Dentre essas ações, as mais citadas foram reutilização de materiais $(78 \%)$ e passeios ecológicos (56\%) (Figura 7a). Ao serem perguntados como a EA é trabalhada na escola (Figura 7b), 100\% dos professores responderam que a EA é trabalhada através de feira de ciências e nas disciplinas. Além dessas atividades, $78 \%$ informaram que também trabalham a EA através de projetos, oficinas, cartazes e panfletos. Quanto as dificuldades para a realização de ações de EA na escola, $67 \%$ deles indicaram a falta de conhecimento na área e, $33 \%$ a falta de materiais didáticos (Figura 7c). Essas afirmações demonstram que oportunizar e estimular a capacitação e o aperfeiçoamento contínuo, corrobora com a melhoria da qualidade do ensino-aprendizagem.

Vale destacar que devido ao seu caráter transformador, a escola apresenta um papel social importantíssimo e, através da inserção da EA crítica e emancipatória em seu planejamento pedagógico, pode-se possibilitar embasamento teórico aos indivíduos para que possam realizar "uma reflexão sobre a sua condição real no ambiente ao qual está inserido" (SANTANA; SANTOS, 2016). Neste sentido, pode-se afirmar que ao sensibilizar os indivíduos para que modifiquem atitudes e valores, na busca por novos hábitos e forma de entendimento da natureza, a EA se apresenta como um importante fator de contribuição à prevenção de desastres naturais. Diante disso, é possível perceber a necessidade da realização de ações de EA com o intuito de gerar uma cultura de prevenção de desastres.

a)

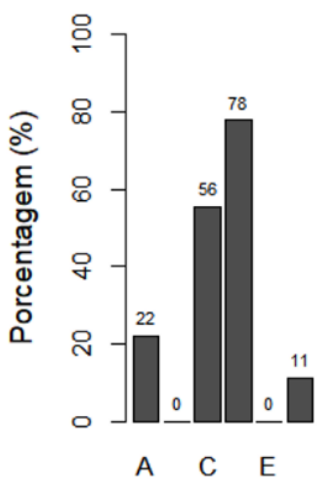

A - Coleta seletiva de lixo;

B - Horta escolar;

C - Passeios ecológicos;

D - Reutilização de materiais:

E - Outras formas;

F - Não realizo. b)

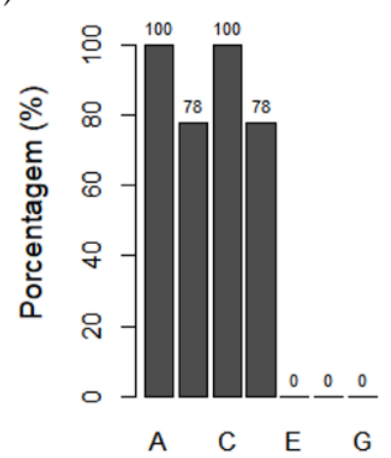

A - Feira de ciências;

B - Projetos/oficinas;

C - Nas disciplinas;

D - Cartazes/panfletos;

E - Jogos educativos;

F - Não é trabalhada;

G - Outras formas. c)

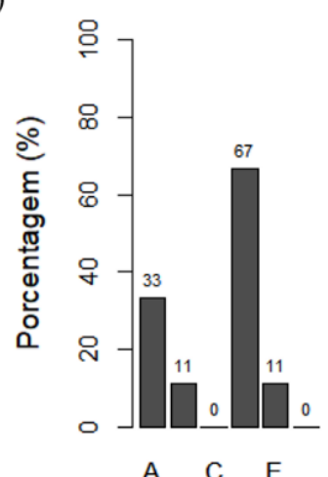

A - Falta de materiais didáticos;

B - Falta de capacitação para os professores;

C - Falta de tempo;

D - Falta de conhecimento na área;

E - Falta de interesse dos alunos;

F - Outras.

Figura 7: Respostas de professores em porcentagem das perguntas: a) Quais ações de Educação Ambiental você realiza ou já realizou na escola? b) Como a Educação Ambiental é trabalhada na escola? c) Em sua opinião, quais as dificuldades encontradas para realizar atividades de Educação Ambiental na escola? (Macaé, RJ, 2018).

Fonte: Elaborado pelo Autores. 
Todas essas respostas reforçam, também, a necessidade de capacitações contínuas direcionadas à educação ambiental e aos desastres naturais. Pois, ao considerar as relações sociais que se estabelecem a partir do modo de produção, de consumo e de trabalho em que estamos inseridos, torna-se cada vez mais urgente e necessário a inserção da EA em todos os espaços, sejam eles formais ou não-formais. Para Carvalho (1998), conhecer o que os docentes pensam sobre a temática ambiental e EA, tem sido indicado como uma estratégia fundamental para a direção que se deve adotar nas ações e propostas de práticas ambientais nas escolas.

A experiência dos professores com relação aos temas ambientais trabalhados na escola, em conjunto com um programa de EA que objetive a formação desses profissionais, pode minimizar essa carência da falta de conhecimento na realização de atividades de EA indicada na Figura 9(c).

\section{Conclusões}

Por meio dos resultados obtidos, foi possível perceber uma carência de trabalhos relacionados aos desastres naturais, embora a maioria dos entrevistados apresentem algum conhecimento sobre o assunto. Grande parte dos alunos entende o que são desastres naturais e indicaram que se percebem como parte integrante do meio ambiente.

Foi possível identificar, também, que as ações de Educação Ambiental têm sido trabalhadas com maior frequência em feiras, passeios ecológicos e por meio reutilização de materiais.

A carência de trabalhos sobre desastres naturais apresentada pelos professores, reforça a necessidade de investimento e incentivo em capacitações e aperfeiçoamento. Uma vez que os professores entrevistados alegaram a falta de conhecimento na área como sendo a principal dificuldade encontrada para realizar atividades de Educação Ambiental.

Vale ressaltar que por apresentar um papel de transformação, a escola se constitui em um espaço de construção cidadã e por meio da inserção da Educação Ambiental pode promover mudanças significativas na sociedade, principalmente em um contexto local. Acredita-se que a integração entre Universidade/escola pode contribuir com essas mudanças por meio das ações de extensão.

Por fim, os resultados sugerem que a escola alvo tem cumprido com seu papel social no desenvolvimento de cidadãos críticos, mas que ainda precisa trabalhar de forma mais intensiva a percepção de risco. Tendo vista que em sua abrangência a Educação Ambiental também inclui a cultura da redução de risco de desastres naturais, sugere-se a realização de atividades lúdicas como forma de desenvolvimento de uma sensibilização ambiental e da percepção de risco de desastres naturais. 


\section{Referências}

AMARAL, R.: GUTJAHR, M.R.: Desastres naturais. São Paulo-SP: IG / SMA. 2011. 100f. (Cadernos de Educação Ambiental, 8).

BUTZKE, I.C. et al. Sugestão de indicadores para avaliação do desempenho das atividades educativas do sistema de gestão ambiental - SGA da Universidade Regional de Blumenau - FURB. Revista Eletrônica do Mestrado em Educação Ambiental. Esp. abr./maio/jun, 2001.

CARVALHO, D.W.; DAMACENA, F.D.L. A intensificação dos desastres naturais, as mudanças climáticas e 0 papel do direito ambiental. Brasília jan./mar. V. 49 n. 193, 2012.

CARVALHO, I.C.M. Em direção ao mundo da vida: interdisciplinaridade e Educação Ambiental / Conceitos para se fazer Educação Ambiental. Brasília: IPÊ Instituto de Pesquisas Ecológicas. 1998. 101f. (Cadernos de Educação Ambiental, 2).

CEEP. Centro de Estatísticas, Estudos e Pesquisas. Disponível em: $<$ http://www.ceperi.ri.gov.br/ceep/info territorios/divis regional.html>. Acesso em: 20 mai. 2020.

FERNANDES, R.S. et al. Uso da percepção ambiental como instrumento de gestão em aplicações ligadas às áreas educacional, social e ambiental. Anais do Encontro Nacional de Pós-Graduação e Pesquissa em Ambiente e Sociedade, v. 2, n. 1, p. 1-15, 2004.

IBGE. Instituto Brasileiro de Geografia e Estatística: Censo Demográfico 2010. Disponível em: <https://cidades.ibge.gov.br/brasil/ri/panorama>. Acesso em: 20 mai. 2020.

KOBIYAMA, M.; MENDONÇA, M.; MORENO, D.A.; MARCELINO, I.P.V.O.; MARCELINO, E.V.; GONÇALVES, E.F.; BRAZETTI, L.L.P.; GOERL, R.F.; MOLLERI, G.S.F.; RUDORFF, F.M. Prevenção de Desastres Naturais: conceitos Básicos. Florianópolis: Ed. Organic Trading, 109 p. 1a edição. 2006.

KOBIYAMA, M; CHECCHIA, T; SILVA, R.V; SCHRÖDER, P.H; GRANDO, A. REGINATTO, G.M.P. Papel da comunidade e da universidade no gerenciamento de desastres naturais. Anais do Simpósio Brasileiro de Desastres Naturais, Florianópolis: GEDN/UFSC, p. 834-846 (CD-ROM), 2004.

SANTANA, G.R.A.; SANTOS, E.B. Conscientização ambiental da população na região central da APA Costa dos Corais. Revista Brasileira de Educação Ambiental, v. 11, n. 2, p. 118-126, 2016.

SOUZA, D.M. Os principais benefícios proporcionados ao trabalhador informal para formalização através do microempreendedor individual. Monografia (Curso de Ciências Contábeis). Curso de Graduação. Universidade Federal de Santa Catarina. Florianópolis, 95f. 2010.

TOALDO, A.M.; MEYNE, L.S.A. Educação Ambiental como instrumento para a concretização do desenvolvimento sustentável. I Congresso Internacional de Direito Ambiental e Ecologia Política - UFSM e III Seminário Ecologia Política e Direito na América Latina. Revista Eletrônica do Curso de Direito. UFSM. v. 8. 2013. 